\title{
İnomplet partisyon tip II bulunan unilateral ve bimodal koklear implant kullanıcılarının konuşma, uzaysal algı ve işitme kalitesinin değerlendirilmesi
}

\author{
Selvet AKKAPLAN@, Merve ÖZBAL BATUK@, Hilal DINÇER D’ALESSANDRO®, Gonca SENNAROĞLU® \\ Hacettepe Üniversitesi Sağlık Bilimleri Fakültesi, Odyoloji Bölümü, Ankara, Türkiye
}

öz

Amaç: Bu çalışmanın amacı, IP-II iç kulak anomalisi olan ve normal kokleaya sahip koklear implant kullanıcılarının çevrelerindeki konuşma ve çevresel sesleri ayırt etme, yönlendirme ve konumlandırma dahil olmak üzere işitme becerilerinin ölçeğe dayalı bir değerlendirmesini yapmaktır.

Gereç ve Yöntemler: Çalışmaya; yaşları 18-55 arasında değişen, IPII iç kulak anomalisi olan 15 katılımcı ve normal kokleaya sahip olan 15 katılımcı olmak üzere toplam 30 koklear implant kullanıcısı dahil edilmiştir. Çalışmaya dahil edilen tüm katılımcılar unilateral Kİ ve bimodal kullanıcılardan oluşmuştur. Katılımcılar, Konuşma, Uzaysal ve İşitme Kalitesi Ölçeği (KUİK) kullanılarak değerlendirilmiştir.

Bulgular: IP-II iç kulak malformasyonu olan koklear implant kullanıcısı bireyler ile normal kokleaya sahip koklear implant kullanıcısı bireyler, işitsel becerilerini bireysel olarak puanladıklarında sonuçların benzer olduğu görülmüştür. Bimodal dinleyicilerin, unilateral Kİ kullanımına göre, tüm alt alanlar ve genel KUİK skorlarının daha iyi olma eğilimi gösterdiği gözlenmiştir.

Sonuç: Seslerin işitilmesinde binaural avantajlardan faydalanmak oldukça önemlidir. Koklear implant kullanıcılarında takip süreçlerinde rutin odyolojik değerlendirme bataryalarının yanı sıra ölçeklerin kullanımının odyologlar için yararlı olacağı düşünülmüştür.

Anahtar Sözcükler: Koklear implant, konuşma algısı, uzaysal alg1, işitme kalitesi
ABSTRACT

\section{Evaluation of the speech, spatial and qualities of hearing in unilateral and bimodal cochlear implant users with incomplete partition type II}

Objective: The aim of this study was to perform a scale-based assessment of the hearing abilities of cochlear implant users with IP type II malformation and normal cochlea, including discrimination, orientation, and positioning of speech and environmental sounds in their environment.

Material and Methods: A total of 30 cochlear implant users, 15 participants with IP-II inner ear anomalies and 15 participants with normal cochlea, aged 18-55 years were included in this study. All participants included in the study are unilateral $\mathrm{CI}$ and bimodal users. Participants were assessed using the Speech, Spatial, and Hearing Qualities Scale (SSQ).

Results: When cochlear implant users with IP-II malformations and cochlear implant users with normal cochlea individually scored auditory abilities, the results were similar. It was observed that bimodal listeners tended to have all subdomains and overall SSQ scores compared to use of unilateral CI.

Conclusion: It is very important to benefit from the advantages of binaural hearing in hearing sounds. It is thought that the use of scales as well as routine audiological evaluation batteries in the follow-up processes of cochlear implant users will be beneficial for audiologists.

Keywords: Cochlear implant, speech perception, spatial perception, hearing quality

Cite this article as: Akkaplan, S., Batuk, M.Ö., Dinçer D'alessandro, H., Sennaroğlu, G. (2021). İnkomplet partisyon tip II bulunan unilateral ve bimodal koklear implant kullanııılarının konuşma, uzaysal algı ve işitme kalitesinin değerlendirilmesi. Turk J Audiol Hearing Res, 4(3):63-68.

\section{GiRiş}

Koklear implantasyon, ileri ve çok ileri derecede sensörinöral işitme kaybı olan bireylerde kullanılan rutin bir prosedür haline gelmiştir (Coudert et al., 2019). Bu müdahale yöntemi aynı zamanda sensörinöral işitme kayıplarının \% 20'sini oluşturan iç kulak anomalileri için de bir tedavi seçeneği oluşturmaktadır (Jackler, Luxford, \& House, 1987). Sennaroğlu ve Saatçi (2002), kemik labirent deformiteleri için yeni bir sınıflandırma ile inkomplet partisyon malformasyonunu (IP) Tip I (IP-I), Tip II (IP-II) ve Tip III (IP-III) olarak tanımlamışlardır. İnkomplet partisyonlar (IP), (X’e bağlı deformite) iç kulağın nadir görülen bir malformasyonudur.
$\mathrm{Bu}$ iç kulak malformasyonlarında ve özellikle IP-I'de genellikle ileri ve çok ileri derecede, IP-II'de hafiften çok ileri dereceye kadar değişiklik göstermekle birlikte IP-III'de ise genellikle ileri derecede mikst tip işitme kaybı gözlenmiştir (Batuk, Çınar, Özgen, Sennaroğlu, \& Sennaroğlu, 2017). İşitme kaybı derecelerine göre odyolojik müdahale seçenekleri farklılık göstermektedir. İşitme kaybı bilateral olduğunda, binaural dinleme önem kazanmaktadır (Erdem \& Çiprut, 2019) . Unilateral dinlemeye göre, binaural dinlemenin birçok avantajı vardır. Sesleri binaural olarak dinlemek, kalabalık ortamlarda birden fazla konuşmacı olduğunda veya ortamda yankılanma olduğunda seslerin daha iyi anlaşılmasını 
sağlar. Seslerin yönünü ve uzaklığını tayin etme yeteneği de büyük ölçüde binaural dinlemeye bağlıdır (Noble, 2010). Binaural dinlemenin avantajlarından faydalanabilmek için rezidüel işitmeye sahip bireylerde bimodal işitme tercih edilmektedir. Bimodal işitme, binaural uyarımın avantajlarından olan sessiz ve gürültülü ortamlarda konuşmayı anlama ve işitsel lokalizasyon becerilerinde iyileşme sağlar (Ching, Incerti, \& Hill, 2004; Ching, Psarros, Hill, Dillon, \& Incerti, 2001; Tyler et al., 2002).

Koklear implant (KI) kullanıcılarının implantasyon sonrasındaki performansının rutin klinik değerlendirmesi, odyolojik test bataryasına ve konuşma algılama testlerine dayanır. Ölçekler, öz değerlendirme araçları arasında önemli bir yer tutmaktadır ve KI kullanıcılarının günlük yaşam aktivitelerindeki performanslarını ve yararlanımlarını değerlendirmeyi sağlayarak yaşam kalitesinin bir ölçüsü olarak kullanılabilir (Cox, Alexander, \& Gray, 2003; Laske et al., 2009; Noble \& Gatehouse, 2006). Rutin klinik değerlendirmelerde kullanılan konuşmayı anlama ve lokalizasyon testleri klinisyenler için daha zaman alıcı olmasının yanı sıra bu testlerin uygulandığı koşullar günlük yaşamın dinleme koşullarını tam olarak temsil etmediği göz önünde bulundurulmalıdır. Buna karşın bireysel değerlendirme araçları olan öznel testlerin (anketler ve/veya derecelendirme ölçekleri) gerçekleştirilmesi kolaydır ve kısa sürede önemli ölçüde veri toplamayı sağlamaktadır (Noble \& Gatehouse, 2006). Üstelik günümüzde sağlık değerlendirmelerinde hastanın öznel deneyimleri giderek önem kazanmaktadır. Yapılan çalışmalarda koklear implantın günlük yaşam üzerindeki etkilerini ölçekler kullanarak gösteren sonuçları ile hastanın bireysel konumunu gerçek dünya işleyişi ve yaşam kalitesi açısından belirlemek mümkündür (Capretta \& Moberly, 2016; Ramakers et al., 2017).

Günümüzde, işitme engeli olan bireyler için birçok bireysel öz değerlendirme aracı mevcuttur. Bunlardan biri de Konuşma, Uzaysal ve İşitme Kalitesi Ölçeği (KUİK)'dir. Literatürde bu ölçek birçok çalışma grubuna uygulanmıştır. Noble ve ark. (2008) ve Berretini ve ark.(2011) (eş zamanlı ya da farklı zamanlarda koklear implant yapılan erişkin hastaları değerlendirmiştir. Bilateral koklear implant kullanan katılımcılarda gürültüdeki konuşma algısı, yön tayini ve işitme kalitesi unilateral koklear implant kullananlara göre daha iyi elde edilmiştir. Erdem ve Çiprut (2019) yaptıkları çalışmada; unilateral, bimodal ve bilateral Kİ kullanıcısı 11-64 yaş aralığındaki 74 kişiyi KUiK Ölçeği kullanarak değerlendirmiş ve bilateral Kİ kullanıcılarının skorlarının, unilateral ve bimodal Kİ kullanıcılardan daha iyi olduğunu belirtmiştir. Rachovitsas ve ark. (2012) yaptıkları çalışmada iç kulak malformasyonu bulunan çocuklarda KI uygulamasının etkinliğini değerlendirmiş ve işitsel algı ve konuşma üretiminde fayda sağladığını belirtmiştir.

Literatürde IP-II iç kulak malformasyonu olan koklear implant kullanıcılarının sağladığı faydayı subjektif olarak değerlendiren ölçeklerin kullanıldığı çalışmalar sınırlıdır. Bu çalışmada; normal kokleaya sahip olan Kİ kullanıcısı bireylerin yanı sıra spesifik olarak IP- II iç kulak malformasyonu olan, unilateral ve bimodal koklear implant kullanıcılarında Konuşma, Uzaysal Alg1 ve İşitme Kalitesi (KUİK) ölçeğini kullanarak işitmenin alt bileşenlerinin ve işitme kalitesini ayrıntılı bir şekilde değerlendirilmesi amaçlanmıştır.

\section{BIREYLER VE YÖNTEM}

$\mathrm{Bu}$ çalışmada veriler toplanırken, katılımcılardan Google Forms aracılığı ile onam alınarak KUiK Ölçeği online olarak uygulanmıştır. Bu çalışma için Hacettepe Üniversitesi Girişimsel Olmayan Araştırmalar Etik Kurulu'ndan ile onay alınmıştır (21/1366).

\section{Bireyler}

$\mathrm{Bu}$ çalışmaya, 18-55 yaş arasındaki 30 birey katılmıştır. Bireyler, 2 alt gruba ayrılmıştır. Birinci grup; normal iç kulak yapısı olan Kİ kullanıcısı bireylerden, ikinci grup ise IP-II iç kulak anomalisi olan Kİ kullanıcısı bireylerden oluşmaktadır. Her iki grupta da 9 unilateral ve 6 bimodal olmak üzere15'er KI kullanan birey yer almıştır.

Çalışmaya katılan bireylerin cinsiyet, yaş, işitme kaybı etyolojisi, işitme kaybı süresi, kontralateral kulakta işitme kaybı derecesi ve implant kullanım sürelerine ait bilgiler Tablo 1 ve Tablo 2 'de verilmiştir.

\section{Yöntem}

Orijinal ismi Speech, Spatial and Qualities of Hearing Scale (SSQ) olan Konuşma, Uzaysal Alg1 ve İşitme Kalitesi Ölçeği (KUIK) Noble ve ark. (2004) tarafından İngiltere'de geliştirilmiştir. Ölçeğin Türkçe geçerlik ve güvenirlik çalışması ise yüksek lisans tezi olarak Kılıç tarafından yayınlanmıştır (Kılıç, Şahin Kamışlı, Gündüz, Bayramoğlu, \& Kemaloğlu, 2021).

49 sorunun bulunduğu ölçek, 'Konuşma Algısı' (KA) 14 soru, 'Uzaysal Algı' (UA) 17 soru ve 'İşitme Kalitesi (IK) 18 soru olmak üzere üç alt bölüme ayrılmıştır. Sorularda, kişinin verili bir durumdaki işitme kalitesini değerlendirmesi istenir. Toplam puan toplam soru sayısına bölünerek Genel KUiK Skoru, alt bölümlerdeki puanlar bölümdeki soru sayısına bölünerek de KA, UA ve İK Skorları elde edilir.

\section{KUiK ölçeği bölümleri:}

1. Konuşma Algısı: 'Konuşma Algısı' ile ilgili alandaki sorular, günlük hayattaki dinleme ortam koşullarını yansıtmaktadır. Bu koşullarındaki zorluklar göz önüne alınarak sorular gerçekçi bir şekilde tasarlanmıştır. Bu alandaki sorular; birbirine rakip olan seslerin durumlarını, sohbete katılan çoklu konuşmacıların varlığını, konuşmada yer alan kişilerin sayısını ve bulunulan ortamın özelliklerini içerir. Maddelerden bazıları binaural işitme sistemininin fonksiyonlarını tespit etmektedir. Bu fonksiyonlar bir sese dikkat ederken diğer sesleri yok sayma, hedef konuşmaya odaklanma, bir konuşmacıdan diğerine hızlı bir şekilde geçen konuşmayı 
Tablo 1: Normal koklea grubuna ait demografik ve odyolojik bilgiler

\begin{tabular}{|c|c|c|c|c|c|c|}
\hline Hastalar & Cinsiyet & Yaş & $\begin{array}{c}\text { İşitme Kaybı } \\
\text { Etyolojisi }\end{array}$ & $\begin{array}{c}\text { İşitme Kaybı Süresi } \\
\text { (Yıl) }\end{array}$ & $\begin{array}{l}\text { Kontralateral Kulakta } \\
\text { İşitme Kaybı Derecesi }\end{array}$ & $\begin{array}{c}\text { İşitme Cihazı } \\
\text { Kullanım Durumu }\end{array}$ \\
\hline
\end{tabular}

Tablo 2: IP-II grubuna ait demografik ve odyolojik bilgiler

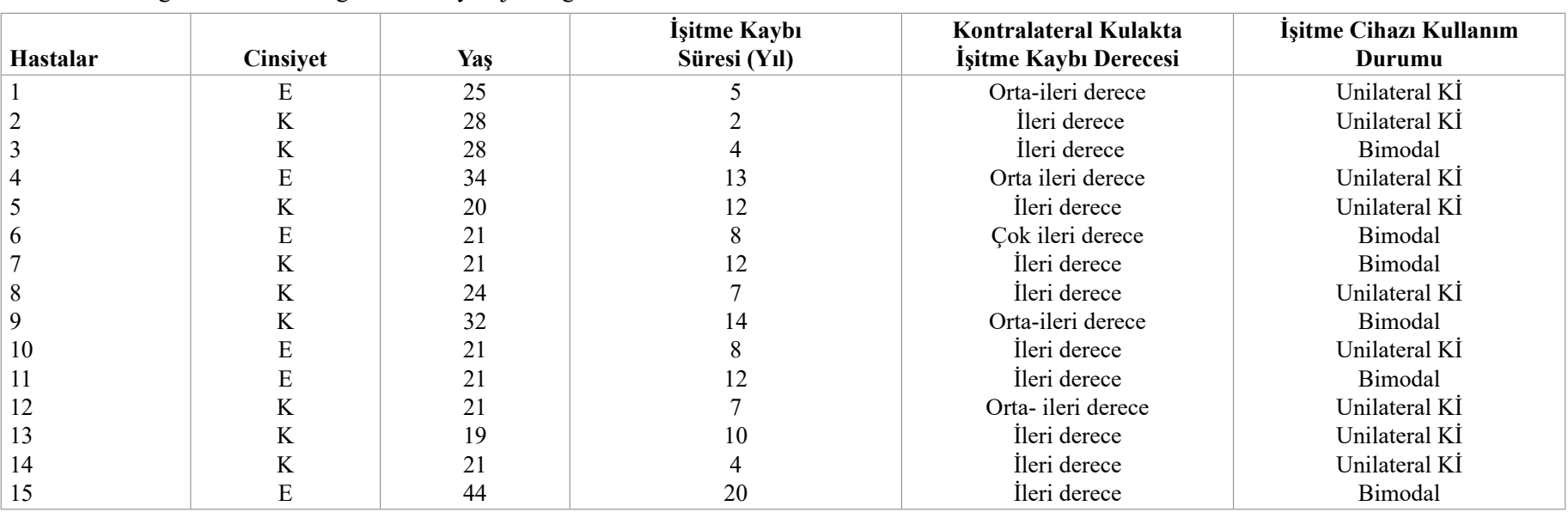

takip etme gibi seçici ve hızlı olmayı gerektiren becerileri içermektedir (Noble \& Gatehouse, 2004).

2. Uzaysal Algı (UA): 'Uzaysal Algı'nın temel unsurları olan yön ve mesafe tayini ile birlikte, hareket bileşeninin de ayrımı yapılmaktadır. İşitme becerisi dinamiktir; gerçek dünyada nesneler ve insanlar hareket halindedir. Bu nedenle uzaysal işitme bu durum göz önüne alınarak değerlendirilmelidir. (Noble \& Gatehouse, 2004).

3. İşitme Kalitesi (IK): İşitilen sesin netliği, doğallığı, anlaşılırlığı ve bir sohbeti takip ederken dinleme eforu sorgulanır. Sorular oluşturulurken günlük hayatta daha sık karşılaşılan müzik ve konuşma sesi örnekleri kullanılmıştır. Kişinin sesinden bulunduğu ruh halinin tahmin edilmeye çalışılması bu bölümde araştırılan önemli konulardan biridir (Noble \& Gatehouse, 2004).

KUIK Ölçeği başlığı altında yer alan soruları içeren form bölümü her bir soru için 0'dan 10'a kadar likert tipte ölçeklendirme içerir. Ölçeğin yanıtlanması öncesinde katılımcılara kısaca gerekli bilgilerin aktarılmasının ardından yanıtlanması esnasında katılımcıların sormak istediği sorular yönlendirme yapılmaksızın cevaplandırılır. Katılımcı ölçeğin her bir maddesi için kendisine en uygun değeri işaretleyerek ölçeği yanıtlama sürecini tamamlar.

\section{BULGULAR}

Çalışmadaki veri analizi, SPSS 23 (IBM Corporations, ABD) programı kullanılarak yapılmıştır. Ölçek verileri sıralı veri oldukları için tanımlayıcı istatistik ölçüsü olarak ortanca, minimum ve maksimum değerler verilmiştir. IP-II iç kulak anomalisi olan ve normal kokleaya sahip bireylerin genel KUIK skorları Şekil 1'de verilmiştir. Genel skorların yanı sıra alt başlıklara ait veriler ayrıntılarıyla Tablo 3 'te gösterilmiştir.

\section{Normal Koklea Grubu}

$\mathrm{Bu}$ gruptaki unilateral Kİ kullanıcılarının genel KUIK ortanca değeri 5.95 olup, skorlar 4.5 ve 7.2 değerleri arasında seyretmiştir. Bimodal dinleyicilerdeki genel KUIKK ortanca değeri ise 6.61 olup, skorlar 5.41 ve 6.89 değerleri arasında gözlenmiştir. Unilateral ve bimodal dinleyicilerin genel KUIK skorları Şekil 2'de verilmiştir.

\section{IP-II Grubu}

$\mathrm{Bu}$ gruptaki unilateral Kİ kullanıcılarının genel KUIKK ortanca değeri 5.91 olup, skorlar 3.77 ve 6.93 değerleri arasında seyretmiştir. Bimodal dinleyicilerdeki genel KUIK ortanca değeri ise 6.48 olup skorlar 0.91 ve 8.44 değerleri arasında gözlenmiştir (Şekil 2). 
Tablo 3. Katılımc1ların KUİK Skorları

\begin{tabular}{|c|c|c|c|c|c|c|}
\hline & \multicolumn{3}{|c|}{ IP-II Grup } & \multicolumn{3}{|c|}{ Normal Koklea Grup } \\
\hline & Ortanca & Min-Maks. & Çey.ara.aralık. & Ortanca & Min-Maks. & Çey.ara.aralık \\
\hline KA & 6.57 & $0.85-7.71$ & $5.21-6.85$ & 6.07 & $2.85-7.03$ & $4.92-6.35$ \\
\hline UA & 6.11 & $4.05-8.82$ & $5.00-7.35$ & 6.00 & $3.05-7.05$ & $4.7-6.64$ \\
\hline İK & 6.38 & $1.11-9.0$ & $5.38-7.66$ & 6.88 & $4.72-8.05$ & $6.22-7.72$ \\
\hline Genel KUİK Skoru & 6.26 & $3.77-9, .8$ & $5.71-6.93$ & 6.06 & $4.51-7.20$ & $6.06-6.75$ \\
\hline
\end{tabular}

Min.: Minimum, Maks.: Maksimum, Çey. Ara.: Çeyrekler arası

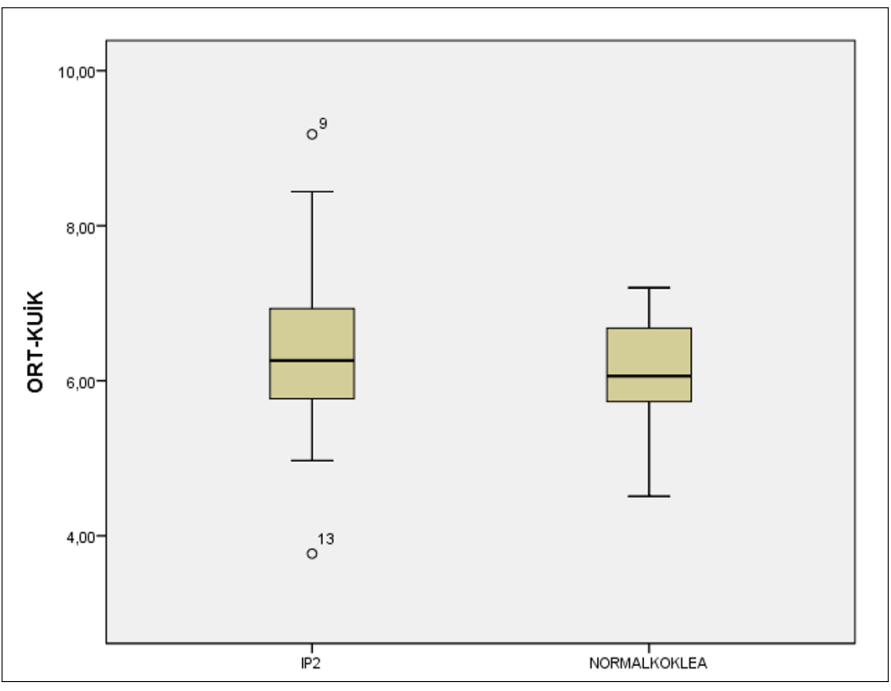

Şekil 1. IP-II Grubu ve Normal Koklea Grubuna ait Genel KUİK Skorları

\section{TARTIŞMA}

Bu çalışmada IP-II iç kulak anomalisi olan ve normal kokleaya sahip unilateral ve bimodal Kİ kullanıcılarının günlük hayatta yaşadıklarıişitseldeneyimlerideğerlendirmekamacıylabireylerin kendilerinin puanladığı KUİK ölçeği ile konuşma algısı, uzaysal alg1 ve işitme kalitesi değerlendirilmiştir. Mevcut bulgularda IP- II grubu ve normal koklea grubundaki Kİ kullanıcılarının genel KUİK skorları ortanca değerlerinin sirasıyla 6.26 ve 6.06 olduğu bulunmuştur. $\mathrm{Bu}$ çalışmadaki IP-II grubu ve normal koklea grubunun genel KUIKK skorlarının birbirleriyle benzerlik gösterdiği gözlenmiştir. Diğer yandan literatüre bakıldığında; unilateral, bimodal ve bilateral Kİ kullanan normal kokleaya sahip bireylerde genel KUIK skorları ortalamaları sırasıyla 4.49, 6.2 ve 8.57 olarak bildirilmiştir (Erdem \& Çiprut, 2019). Ancak bizim çalışmamızdaki unilateral Kİ kullanıcılarının genel KUİK skorlarının Erdem ve Çiprut (2019) çalışmasındaki bulgulardan daha iyi, bimodal dinleyicilerdeki sonuçların ise benzer olduğu gözlenmiştir. Unilateral Kİ kullanan bireylerin sonuçlarındaki bu fark her iki çalışmadaki örneklem sayısının az olması ve KI dinleyicilerindeki performans üzerinde anlamlı etki gösterebilen demografik değişkenler ve odyolojik faktörlerden kaynaklanmış olabilir.

Literatürde iç kulak anomalisi olan Kİ kullanıcılarının işitsel becerilerinin subjektif olarak değerlendirildiği çalışmalar oldukça sinırlıdır. Kamogashira ve ark. (2016), koklear implantasyondan sonra iç kulak anomalilerinin işitsel becerilerin gelişimi

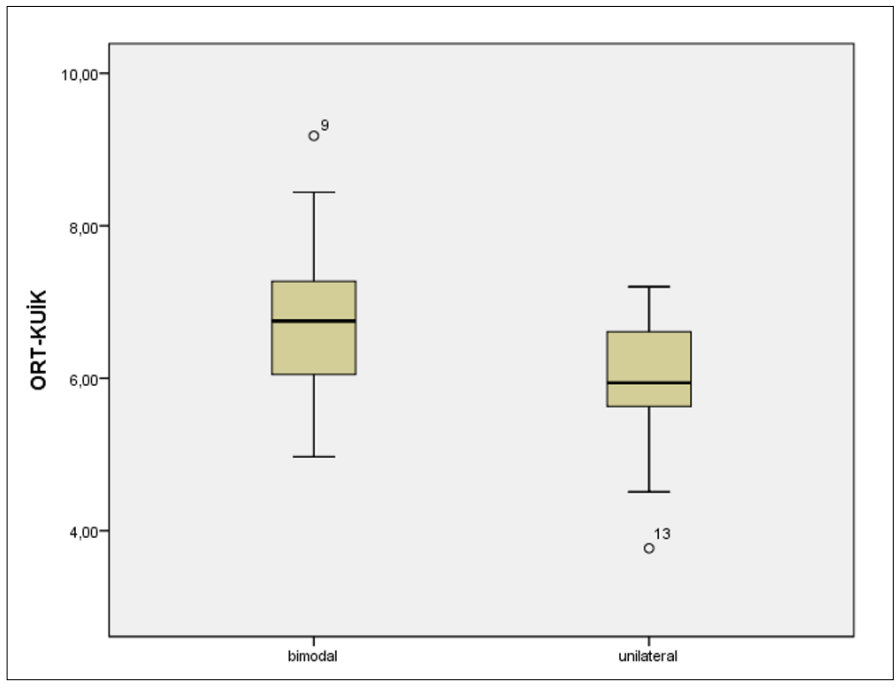

Şekil 2. Unilateral ve Bimodal Dinleyicilerin Genel KUİK Skorları

üzerindeki etkisini araştırmak için; iç kulak anomalisi olan, 4 yaşından önce Kİ uygulanmış ve 2 yıldan fazla takip edilen 20 çocuğun işitsel becerilerini Anlamlı İşitsel Deneyim Skalası (MAIS) ile değerlendirmiş ve iç kulak anomalisi olan çocuklar, Kİ uygulamasından 1 yll sonra işitme eşiklerinde ve MAIS skorlarında anlamlı iyileşme gösterdiği rapor edilmiştir Isaiah ve ark. (2017)yaptı̆̆ çalışmada pediatrik grupta konuşma algısı becerisini değerlendirmiş ve tek anomalinin geniş vestibüler akuadukt olan grupta sonuçların herhangi bir iç kulak anomalisi olmayan grup ile benzer olduğunu belirtmiştir. Mevcut çalışmada IP-II Grubu ile Normal Koklea Grubuna ait KUIK genel ve alt başlık skorları arasında anlamlı fark bulunmamıştır. IP-II anomalisi tüm kokleovestibüler anomaliler arasında normal kokleaya en çok benzerlik gösteren anomali tipidir. Bu nedenle elde edilen skorların birbirine benzer elde edilmiştir. Bu benzerliğin çalışmaya katılan her iki gruptaki bireylerin işitme kaybı başlangıç yaşı ve işitme kaybı derecesi benzerliğinden kaynaklanabileceği öngörülmüştür. Örneklem sayısının sınırlı olmasının da elde edilen sonuçta etkili olabileceği düşünülmüştür.

Çalışmamızda, normal kokleaya sahip kişiler ile karşılaştırdığımız IP-II malformasyonu olan bireylerin koklea iç organizasyonu, IP-I malformasyonlarına göre daha gelişmiş olup, IP-I malformasyonlarında rezidüel nöral fonksiyonun daha zayıftır. (Batuk et al., 2017). Bazal dönüşün gelişmesi nedeniyle IP-II hastalarında modiolus görülebilir ve rezidüel işitme IP-I hastalarına göre daha iyidir (Berrettini, Forli, De Vito, Bruschini, 
\& Quaranta, 2013). Çalışmamızda IP-I malformasyonu olan KI kullanıcıları yerine IP-II malformasyonu olan bireyler ile normal kokleaya sahip bireyler karşılaştırılmıştır. Böylece koklear anomalinin etkisini değerlendirmek amaçlanmıştır.

Çalışmamızda, katılımcıların KUIKK Ölçeğine verdiği cevaplar doğrultusunda, konuşma algısı, uzaysal alg1 ve işitme kalitesini değerlendirildiğinde, bimodal kullanımın unilateral koklear implant kullanımına göre tüm alt alanlar ve genel KUİK skorlarının daha iyi olma eğilimi gösterdiği gözlenmiştir. Literatüre bakıldığında birçok çalışmada, bimodal ve unilateral koklear implant kullanıcılarının işitsel becerileri farklı objektif ve subjektif değerlendirme yöntemleri ile incelendiği görülmektedir. Bimodal kullanımın, unilateral koklear implant kullanımına göre; kelime tanıma, dinleme eforu, rehabilitasyondan elde edilen fayda, müzikal alg1 ve lokalizasyon gibi işitsel becerilerde daha iyi olduğu farklı çalışmalarda gösterilmiştir (Choi et al., 2016; Devocht, Janssen, Chalupper, Stokroos, \& George, 2017; Hinder, Linder, SchlegelWagner, \& Candreia, 2017; Marsella et al., 2015; Zhang, Su, Wang, \& Zhou, 2016). Mevcut çalışmada unilateral kullanıcılar ve bimodal kullanıcılar arasında skorlar açısından istatistiksel olarak anlamlı bir fark olup olmadığı her bir gruptaki örneklem sayısı az olması nedeniyle değerlendirilememiştir. Ancak daha önceki bulgular ve mevcut çalışmadaki eğilim göz önüne alındığında bimodal koklear implant kullanıcılarının unilateral koklear implant kullanıcılarına kıyasla konuşma algısı, uzaysal işitme ve işitme kalitesi açısından daha iyi performansa sahip olduğunu söylenebilir (Erdem \& Çiprut, 2019). Bu anlamda, tıbbi veya ekonomik nedenlerle bilateral implantasyon uygulanamayan Kİ kullanıcılarının kontralateral kulakta işitme cihazı kullanmalarını önermek önemli görünmektedir.

Bimodal dinleyicilerde, performansı etkileyen en önemli unsurlardan biri işitme cihazı kullanılan kulaktaki rezidüel işitme miktarı olduğu bilinmektedir (Dincer D'Alessandro et al., 2018). Ancak pandemi koşulları nedeniyle veriler online ortamda toplanmış olup katılımcıların kontralateral kulaktaki rezidüel işitme miktarı değerlendirilememiştir. Bu nokta da göz önünde bulundurularak daha geniş bir örneklem grubunda yürütülecek çalışmalara faydalı bilgiler sağlayabilir. Özellikle literatürde IP-II iç kulak anomalisi olan Kİ kullanıcısı bireylerde yapılan subjektif değerlendirme çalışmaları oldukça sınırlıdır. $\mathrm{Bu}$ anlamda mevcut çalışma bilindiği kadarıyla, KUIKK gibi yeni bir ölçek aracıllığıla IP-II iç kulak anomalisi olan koklear implant kullanıcısı bireylerin günlük yaşamdaki öznel deneyimlerini normal kokleası olanlar ile karşılaştırmalı olarak değerlendirildiği ilk çalışmadır.

\section{SONUÇ}

IP-II iç kulak anomalisi olan koklear implant kullanıcısı bireyler ile normal kokleaya sahip koklear implant kullanıcısı bireyler, işitsel becerilerini bireysel olarak puanladıklarında sonuçların benzer olduğu görülmüştür. Koklear implant kullanıcıları günlük yaşamdaki işitsel deneyimlerini öznel olarak puanladıklarında, bimodal kullanımın unilateral koklear implant kullanımına göre daha iyi olduğu sonucuna ulaşılmıştır. Seslerin işitilmesinde binaural avantajlardan faydalanmak oldukça önemlidir. Koklear implant kullanıcılarında takip süreçlerinde rutin odyolojik değerlendirme bataryalarının yanı sıra ölçeklerin kullanımının odyologlar için yararlı olacağı düşünülmüştür.

Etik Kurul Onayı: Çalışma, Hacettepe Üniversitesi Girişimsel Olmayan Araştırmalar Etik Kurulu tarafından onaylandı. Bu çalışma için 21/1366 karar numarası ile onay alınmıştır.

Hakem Değerlendirmesi: Dış Bağımsız.

Yazar Katkıları: Fikir- MÖ BATUK; Tasarım- GS, MÖ BATUK, HD; Denetleme- GS, MÖ BATUK, HD; Veri Toplanması ve/veya İşlemesi- SA; Analiz ve/veya Yorum- SA, MÖ BATUK, HD; Literatür Taraması- SA; Yazıyı Yazan- SA.

Çıkar Çatışması: Yoktur.

Finansal Destek: Finansal destek kullanılmamıştır.

Ethics Committee Approval: The study was approved by the Hacettepe University Non-Interventional Research Ethics Committee. Approval was obtained for this study with decision number 21/1366.

Peer-review: Externally peer-reviewed.

Author Contributions: Concept- MÖ BATUK; Design- GS, MÖ BATUK, HD; Supervision- GS, MÖ BATUK, HD; Data Collection and/or Processing-SA; Analysis and/ or Interpretation- SA, MÖ BATUK, HD; Literature Search- SA; Writing Manuscript- SA.

Conflict of Interest: No conflict of interest.

Financial Disclosure: None.

\section{KAYNAKLAR}

Batuk, M. Ö., Çınar, B. Ç., Özgen, B., Sennaroğlu, G., \& Sennaroğlu, L. (2017) Audiological and radiological characteristics in incomplete partition malformations. The journal of international advanced otology, 13(2), 233.

Berrettini, S., Baggiani, A., Bruschini, L., Cassandro, E., Cuda, D., Filipo, R., . . . Forli, F. (2011). Systematic review of the literature on the clinical effectiveness of the cochlear implant procedure in adult patients. Acta Otorhinolaryngol Ital, 31(5), 299-310.

Berrettini, S., Forli, F., De Vito, A., Bruschini, L., \& Quaranta, N. (2013). Cochlear implant in incomplete partition type I. Acta Otorhinolaryngol Ital, 33(1), 56-62.

Capretta, N. R., \& Moberly, A. C. (2016). Does quality of life depend on speech recognition performance for adult cochlear implant users? Laryngoscope, 126(3), 699-706. https://doi.org/10.1002/lary.25525

Ching, T. Y., Incerti, P., \& Hill, M. (2004). Binaural benefits for adults who use hearing aids and cochlear implants in opposite ears. Ear Hear, 25(1), 9-21. https://doi. org/10.1097/01.Aud.0000111261.84611.C8

Ching, T. Y., Psarros, C., Hill, M., Dillon, H., \& Incerti, P. (2001). Should children who use cochlear implants wear hearing aids in the opposite ear? Ear Hear, 22(5), 365-380. https://doi.org/10.1097/00003446-200110000-00002

Choi, S. J., Lee, J. B., Bahng, J., Lee, W. K., Park, C. H., Kim, H.-J., \& Lee, J. H. (2016). Effect of low frequency on speech performance with bimodal hearing in bilateral severe hearing loss. The Laryngoscope, 126(12), 2817-2822. https://doi.org/10.1002/lary.26014

Coudert, A., Vigier, S., Scalabre, A., Hermann, R., Ayari-Khalfallah, S., \& Truy, E. (2019). Analysis of inner ear malformations associated with a facial nerve anomaly in 653 children fitted with a cochlear implant. Clin Otolaryngol, 44(1), 96-101. https://doi.org/10.1111/coa.13246

Cox, R. M., Alexander, G. C., \& Gray, G. A. (2003). Audiometric correlates of the unaided APHAB. J Am Acad Audiol, 14(7), 361-371.

Devocht, E. M. J., Janssen, A. M. L., Chalupper, J., Stokroos, R. J., \& George, E. L. J. (2017). The Benefits of Bimodal Aiding on Extended Dimensions of Speech Perception: Intelligibility, Listening Effort, and Sound Quality. Trends in Hearing, 21, 2331216517727900. https://doi.org/10.1177/2331216517727900

Dincer D’Alessandro, H., Ballantyne, D., Boyle, P. J., De Seta, E., DeVincentiis, M., \& Mancini, P. (2018). Temporal Fine Structure Processing, Pitch, and Speech Perception in Adult Cochlear Implant Recipients. Ear Hear, 39(4), 679-686. https://doi.org/10.1097/aud.0000000000000525

Erdem, B. K., \& Çiprut, A. (2019). Evaluation of Speech, Spatial Perception and Hearing Quality in Unilateral, Bimodal and Bilateral Cochlear Implant Users. Turkish archives of otorhinolaryngology, 57(3), 149-153. https://doi. org/10.5152/tao.2019.4105 
Hinder, D., Linder, T. E., Schlegel-Wagner, C., \& Candreia, C. (2017). Benefit of Bimodal Stimulation with Cochlear Implant and Hearing Aid in Elderly Patients. Laryngo-rhino-otologie, 96(7), 456-460.

Isaiah, A., Lee, D., Lenes-Voit, F., Sweeney, M., Kutz, W., Isaacson, B., . . . Lee, K. H. (2017). Clinical outcomes following cochlear implantation in children with inner ear anomalies. International journal of pediatric otorhinolaryngology, 93, 1-6.

Jackler, R. K., Luxford, W. M., \& House, W. F. (1987). Congenital malformations of the inner ear: a classification based on embryogenesis. Laryngoscope, 97(3 Pt 2 Suppl 40), 2-14. https://doi.org/10.1002/lary.5540971301

Kamogashira, T., Akamatsu, Y., Kashio, A., Ogata, E., Karino, S., Kakigi, A., . . . Yamasoba, T. (2016). Development of auditory skills after cochlear implantation in children with inner ear malformations. Acta Oto-Laryngologica, 136(1), 7882. https://doi.org/10.3109/00016489.2015.1087047

Kılıç, N., Şahin Kamıșlı, G. İ., Gündüz, B., Bayramoğlu, İ., \& Kemaloğlu, Y. K. (2021). Turkish Validity and Reliability Study of the Speech, Spatial and Qualities of Hearing Scale. Turkish archives of otorhinolaryngology, 59(3), 172-187. https://doi.org/10.4274/tao.2021.2021-4-3

Laske, R. D., Veraguth, D., Dillier, N., Binkert, A., Holzmann, D., \& Huber, A. M. (2009). Subjective and objective results after bilateral cochlear implantation in adults. Otol Neurotol, 30(3), 313-318. https://doi.org/10.1097/ MAO.0b013e31819bd7e6

Marsella, P., Giannantonio, S., Scorpecci, A., Pianesi, F., Micardi, M., \& Resca, A. (2015). Role of bimodal stimulation for auditory-perceptual skills development in children with a unilateral cochlear implant. Acta Otorhinolaryngologica Italica, 35(6), 442.

Noble, W. (2010). Assessing binaural hearing: results using the speech, spatial and qualities of hearing scale. J Am Acad Audiol, 21(9), 568-574. https://doi. org/10.3766/jaaa.21.9.2

Noble, W., \& Gatehouse, S. (2004). Interaural asymmetry of hearing loss, Speech, Spatial and Qualities of Hearing Scale (SSQ) disabilities, and handicap. International Journal of Audiology, 43(2), 100-114. https://doi. org/10.1080/14992020400050015
Noble, W., \& Gatehouse, S. (2006). Effects of bilateral versus unilateral hearing aid fitting on abilities measured by the Speech, Spatial, and Qualities of Hearing scale (SSQ). International Journal of Audiology, 45(3), 172-181. https://doi. org/10.1080/14992020500376933

Noble, W., Tyler, R., Dunn, C., \& Bhullar, N. (2008). Unilateral and bilateral cochlear implants and the implant-plus-hearing-aid profile: comparing selfassessed and measured abilities. Int J Audiol, 47(8), 505-514. https://doi. org/10.1080/14992020802070770

Rachovitsas, D., Psillas, G., Chatzigiannakidou, V., Triaridis, S., Constantinidis, J., \& Vital, V. (2012). Speech perception and production in children with inner ear malformations after cochlear implantation. Int J Pediatr Otorhinolaryngol, 76(9), 1370-1374. https://doi.org/10.1016/j.ijporl.2012.06.009

Ramakers, G. G. J., Smulders, Y. E., van Zon, A., Van Zanten, G. A., Grolman, W., \& Stegeman, I. (2017). Correlation between subjective and objective hearing tests after unilateral and bilateral cochlear implantation. BMC Ear Nose Throat Disord, 17, 10. https://doi.org/10.1186/s12901-017-0043-y

Sennaroglu, L., \& Saatci, I. (2002). A New Classification for Cochleovestibular Malformations. The Laryngoscope, 112(12), 2230-2241. https://doi. org/10.1097/00005537-200212000-00019

Tyler, R. S., Parkinson, A. J., Wilson, B. S., Witt, S., Preece, J. P., \& Noble, W. (2002). Patients utilizing a hearing aid and a cochlear implant: speech perception and localization. Ear Hear, 23(2), 98-105. https://doi.org/10.1097/00003446200204000-00003

Zhang, J., Su, J., Wang, M., \& Zhou, H. (2016). Study on bimodal stimulation for aural rehabilitationdevelopmentin infants with a unilateral cochlear implant. Lin Chuang er bi yan hou tou Jing wai ke za zhi= Journal of Clinical Otorhinolaryngology, Head, and Neck Surgery, 30(22), 1774-1777. 